Ambiente \& Água - An Interdisciplinary Journal of Applied Science
ISSN 1980-993X - doi:10.4136/1980-993X
www.ambi-agua.net
E-mail: ambi.agua@gmail.com

\title{
Aspectos socioambientais e de saúde das quebradeiras de coco babaçu na microrregião do Bico do Papagaio, Tocantins, Brasil
}

\author{
doi:10.4136/ambi-agua.1920
}

Received: 02 Oct. 2016; Accepted: 28 Nov. 2016

\author{
Iracema Sousa Santos Mourão $^{1^{*}}$; Julio Cesar Raposo de Almeida ${ }^{1}$; \\ Mariko Ueno ${ }^{1}$; Herminia Yohko Kanamura ${ }^{1}$ \\ ${ }^{1}$ Universidade de Taubaté (UNITAU), Taubaté, SP, Brasil \\ Programa de Pós-Graduação em Ciências Ambientais \\ *Autor correspondente: e-mail: iracemasts@ hotmail.com, \\ jcraposo@uol.com.br,maritieue@gmail.com, \\ herminia.kanamura@pq.cnpq.br
}

\section{RESUMO}

Neste estudo objetivou-se analisar os aspectos socioambientais e de saúde das quebradeiras de coco babaçu da Associação Regional das Mulheres Trabalhadoras Rurais do Bico do Papagaio (ASMUBIP - TO). A quebra do coco babaçu é uma atividade penosa, quase sempre realizada por mulheres de baixa renda e que vivem na área rural com a utilização de instrumental técnico rudimentar, pode causar lesões nas mãos e/ou em outras partes do corpo. Além disso, pode provocar alterações orgânicas em decorrência de posturas inadequadas e de movimentos repetitivos. Trata-se de uma pesquisa qualiquantitativa, cujos dados foram coletados em campo a partir de um formulário estruturado com questões fechadas e abertas. Foram mencionados pelas informantes 11 sintomas que elas atribuem à quebra do babaçu entre os quais: dores de coluna; dores nas costas; dores nos rins; dores nas juntas; dores no corpo; problemas de vista; inflamação na garganta; mioma uterino; anemia e doenças de pele. A quebra do babaçu é muito importante para as quebradeiras por contribuir para sua sobrevivência. Por outro lado, as quebradeiras contribuem para a preservação dos babaçuais através de sua atuação política. Elas não dissociam a vida das florestas de babaçu de sua própria vida.

Palavras-chave: aspectos socioambientais, doenças ocupacionais, trabalhadoras rurais.

\section{Socio-environmental aspects and health of women working as babaçu coconut shellers in Bico do Papagaio, Tocantins, Brazil}

\section{ABSTRACT}

This study analyzed the environmental and health aspects related to babaçu coconut breakers belonging to the Regional Association of Rural Female Workers, Tocantins State (Portuguese acronym "ASMUBIP - TO"). The breaking of the babaçu coconut is a painful activity, often performed by women of low income, living in rural areas and using rudimentary techniques and equipment. The activity can cause injuries to the hands or other parts of body. In addition, it can cause organic changes due to awkward postures and repetitive movements. The study was both qualitative and quantitative. Data were collected in 
the field using a structured form with open and closed questions. The respondents mentioned nine symptoms related to breaking the babaçu: back pain, kidney pain, joint pain, body aches, eye problems, sore throat, uterine fibroids, anemia and skin diseases. This work is vital to the economic survival of the breakers. On the other hand, the ASMUBIP contributes to the preservation of babaçu through its political action. The lives of the workers and of the babaçu forests are therefore intricately intertwined.

Keywords: babaçu coconut, occupational diseases, rural workers, social-environmental aspects.

\section{INTRODUÇÃO}

Desde 2009 a $1^{\text {a }}$ Conferência Nacional de Saúde Ambiental reforçou o forte caráter interdisciplinar e intersetorial da Saúde Ambiental apontando a necessidade de reflexão sobre os determinantes socioambientais da saúde, de forma a garantir a construção de diretrizes e ações de vigilância e promoção da saúde (Porto e Milanez, 2009).

O processo saúde-doença dos trabalhadores na agricultura familiar e no extrativismo de produtos como o babaçu, insere-se no âmbito da saúde coletiva reconhecendo que o processo de adoecimento do trabalhador não está relacionado apenas a fatores ambientais, externos ao trabalhador, mas também às relações de produção (SATO et al., 2006).

O babaçu é uma palmeira monocaule, com até $20 \mathrm{~m}$ de altura e estipe liso medindo até $41 \mathrm{~cm}$ de diâmetro, com frutos oblongos-elipsóides lisos, com 11,3 x 6,3 cm de diâmetro, de coloração marrom na maturidade, o coco babaçu. As florestas de babaçu estão mais concentradas nas regiões Norte e Nordeste do Brasil (Miranda et al., 2001).

O estado de Tocantins é o quarto produtor brasileiros de amêndoas de babaçu (IBGE, 2010), cuja extração depende do trabalho das chamadas quebradeiras de coco, que são trabalhadoras rurais autônomas que se dedicam ao extrativismo primário dessa essência vegetal. Elas constituem uma categoria profissional que tem como principais atividades, a coleta, a extração e, por vezes, o beneficiamento das amêndoas do coco babaçu.

Do ponto de vista ambiental, esta atividade pode ser considerada sustentável, uma vez que a coleta e a quebra do coco babaçu promove transformações socioambientais no meio rural, sem prejuízos para as florestas de babaçu. Em torno do babaçu mobilizaram-se forças sociais e políticas com a finalidade de garantir o acesso das quebradeiras às florestas. Um exemplo é a ASSEMA - Associação em Áreas de Assentamento do Estado do Maranhão (MA), instituição que, conforme Borelli (2012), aproximou as quebradeiras do "Movimento Interestadual das Quebradeiras de coco babaçu, que reúne mulheres das regiões do Maranhão, Tocantins, Pará e Piauí".

No caso da região do Bico do Papagaio, no Estado do Tocantins, a luta das quebradeiras de babaçu resultou na criação da Reserva Extrativista Extremo do Norte criada pelo Decreto $\mathrm{n}^{\circ} 535$ em 20 de maio de 1992 (Brasil, 2005). As quebradeiras de babaçu do município de São Miguel, Estado do Tocantins, estão organizadas através da ASMUBIP, instituição, segundo Silva Neto (2008), criada com a finalidade de valorizar o extrativismo do babaçu e garantir o acesso das quebradeiras a uma fonte de renda capaz de contribuir para a manutenção de suas famílias.

Contudo, a quebra artesanal do babaçu, como muitas outras atividades rurais, se configura como uma atividade árdua e penosa, pois ainda é realizada a partir de técnicas rudimentares e pouco aparato tecnológico, exigindo grande esforço físico das quebradeiras e expondo-as a riscos de acidentes e ao desenvolvimento de doenças ocupacionais.

Neste estudo, teve-se por objetivo descrever aspectos socioambientais e de saúde das quebradeiras de coco babaçu procurando verificar a possível relação entre as atividades laborais e a prevalência de doenças ocupacionais entre as quebradeiras de coco babaçu 
reunidas na Associação Regional das Mulheres Trabalhadoras Rurais do Bico do Papagaio (ASMUBIP-TO).

\section{MATERIAL E MÉTODOS}

A pesquisa descritiva, analítica e transversal foi realizada na microrregião do Bico do Papagaio (TO), no município de São Miguel do Tocantins, que possuiárea total de 398.820 $\mathrm{Km}^{2}$ onde vivem 10.481 habitantes (IBGE, 2010).

A população pesquisada foi constituída por mulheres que trabalham com a quebra do coco babaçu cadastradas na Associação Regional das Mulheres Trabalhadoras Rurais do Bico do Papagaio (ASMUBIP-TO) A ausência de publicações de dados quantitativos de quebradeiras de coco no município propiciou a adoção da amostragem não probabilística intencional (Santos, 2011). Das 189 trabalhadoras selecionou-se um grupo de 31 quebradeiras de coco babaçu.

Os dados foram coletados durante o ano de 2012 utilizando-se como instrumento de coleta de dados em campo um formulário composto com questões fechadas e abertas, de forma que a pesquisa se constitui como quantiqualitativa. $\mathrm{O}$ formulário foi estruturado com 7 categorias de análise, os quais serviram para agrupar, no âmbito de cada um, as informações que mantêm afinidades entre si:

1. Fatores humanos no trabalho.

2. Condições de trabalho.

3. Condições psicossomáticas (saúde).

4. Condições socioeconômicas e culturais.

5. Condições de ambiente.

6. Segurança no trabalho.

7. Treinamento.

A análise das respostas foi realizada de acordo com o método da análise de conteúdo segundo Bardin (2011).

\section{RESULTADOS E DISCUSSÃO}

Das 31 mulheres que participaram deste estudo 22,6\% têm entre 20 aos 30 anos; 9,7\% inserem-se na faixa dos 31 aos 40 anos; 22,6\% distribuem-se pelo intervalo dos 41 aos 50 anos; $16,1 \%$ têm de 51 a 60 anos; 9,7\% têm de 61 a 70 anos e 19,3\% têm mais de 70 anos.

Em relação ao nível de escolaridade das informantes, pode ser considerado baixo, pois somados os percentuais das informantes que não foram alfabetizadas com as que cursaram o ensino fundamental incompleto alcança-se o índice de 74,4\%. Algumas possuem o ensino médio incompleto e completo e pelo menos uma delas, possui graduação em nível superior.

Em relação ao tempo em que se dedicam a atividades relacionadas à quebra do coco babaçu, apenas 6,5\% das informantes declararam que de 1 a 10 anos. As demais estão bem distribuídas nas faixas de 11 a 20 e de 41 a 50 anos. O percentual mais significativo, 29\% é constituído pelas quebradeiras que se dedicam a atividade há mais de 51 anos.

Interrogadas sobre os motivos que as levaram a se dedicarem, profissionalmente à quebra do babaçu as respostas, em números absolutos, são as seguintes: 26 das informantes declararam que por necessidade financeira e 15 porque gostam do que fazem. Embora possa haver diversos motivos para que alguém se dedique à quebra do babaçu, ela é quase sem 
realizada por pessoas muito pobres que teriam dificuldade de acesso a outras oportunidades de emprego e renda (Silva, 2006a; Albiero et al., 2007).

Solicitadas a informar sobre as dificuldades e outros estresses (Tabela 1) encontrados para realizar a quebra do coco babaçu, as informantes deram as respostas seguintes: 5 informantes declararam que é juntar e transportar o coco; 15 declararam que transportar; 7 declararam que dificuldade de acesso; 5 declararam que a maior dificuldade é a saúde deficiente e 2 informantes não deram nenhuma resposta. Neste caso, algumas informantes marcaram mais de uma das alternativas que lhes foram apresentadas, o que elevou o número de respostas para 34.

As dificuldades de acesso podem referir-se às estradas e/ou às florestas de babaçu, as quais quase sempre se encontram em propriedades particulares, cujo acesso das quebradeiras, pode não ser bem visto pelos proprietários. Já as dificuldades relacionadas ao transporte do coco "in natura", cabe esclarecer que ele é quase sempre feito com a utilização de animais de carga, de forma especial, o jumento (Albiero et al., 2007).

Tabela 1. Fatores que mais geraram estresse no ambiente de trabalho das quebradeiras de coco babaçu associadas da ASMUBIP no município de São Miguel, Estado do Tocantins, Brasil ( $\mathrm{N}^{\circ}$. de informantes $=31$ ).

\begin{tabular}{lcc}
\hline Item & Frequência & $\%$ \\
\hline Longa jornada de trabalho & 20 & 23,5 \\
Recursos de materiais insuficientes & 02 & 2,3 \\
Dificuldade de vender o fruto de seu trabalho & 12 & 14,1 \\
Remuneração injusta pelo fornecimento produto de seu trabalho & 27 & 31,8 \\
Inexistência de perspectiva de crescimento profissional & 10 & 11,8 \\
Insatisfação do trabalho & 14 & 16,5 \\
\hline TOTAL & $\mathbf{8 5}$ & $\mathbf{1 0 0 , 0}$ \\
\hline
\end{tabular}

Um item importante para este estudo: a saúde das quebradeiras foi mencionado por apenas 5 informantes. Neste caso, os problemas de saúde podem interferir pouco em suas atividades profissionais ou domésticas, o que pode indicar que se trata de pessoas sadias ou que, pela persistência dos sintomas, eles passam a ser percebidos como normais.

Entretanto, como afirma Dias (2012), quem mantém contato com as quebradeiras, percebe que elas se queixam de diversos problemas de saúde, dentre eles, hérnia, dores de coluna creditadas à forma como o coco é quebrado e com mutilações em dedos das mãos. Por sua vez Pinto et al. (2010) afirmam que a quebra tradicional do babaçu realizada pelas quebradeiras, com um machado e um porrete de madeira, se caracteriza pela baixa produtividade, pela insalubridade e pelo risco de acidentes.

Com relação ao desenvolvimento de doença associado a pratica de quebra de coco babaçu $58,1 \%$ responderam sim e $41,9 \%$ responderam não, ou seja mais da metade das informantes admitiram a possibilidade de ter desenvolvido algum tipo de adoecimento em consequência de sua atividade com o babaçu. Solicitou-se que informassem que doenças haveriam desenvolvido em decorrência de sua atividade profissional, cujas respostas são apresentadas nas Tabelas 2 e 3 . 
Tabela 2. Manifestação espontânea de doenças desenvolvidas em quebradeiras de coco babaçu associadas da ASMUBIP por causa de sua atividade laboral no município de São Miguel, Estado do Tocantins, Brasil $\left(\mathrm{N}^{\circ}\right.$. de informantes $\left.=31\right)$.

\begin{tabular}{lcc}
\hline Item & Frequência & $\%$ \\
\hline Dores de coluna & 09 & 29,0 \\
Dores nos rins & 01 & 3,2 \\
Dores nas juntas & 03 & 9,7 \\
Dores no corpo & 01 & 3,2 \\
Problemas de vista & 01 & 3,2 \\
Inflamação na garganta & 01 & 3,2 \\
Miomas uterinos & 02 & 6,5 \\
Anemia & 01 & 3,2 \\
Doenças de pele & 01 & 3,2 \\
Não responderam & 11 & 35,5 \\
\hline TOTAL & $\mathbf{3 1}$ & $\mathbf{1 0 0 , 0}$ \\
\hline
\end{tabular}

Reconhece-se que quase todos os sintomas informados podem estar relacionados com o desempenho de sua atividade, o que demonstra um nível importante de consciência das informantes, o que, em tese, poderia resultar em maiores cuidados com a saúde.

Além disso, não é difícil encontrar pessoas que vivenciam processos de adoecimentos que não lhes impede de realizar suas atividades diárias, de modo que a doença passa a ser tida como algo normal. De acordo com Silva (2006b) existem clientes com patologias crônicas que se consideram sadios. Outros "aparentando saúde" vivenciam um problema de ordem pessoal, tendo tamanha relevância que arruína o seu bem-estar.

Interrogadas sobre os fatores ambientais que mais interferem na condição de saúde das quebradeiras de coco babaçu, $12,9 \%$ das informantes declararam radiação solar; $22,6 \%$ temperatura e $64,5 \%$ as chuvas. As quebradeiras de coco babaçu muitas vezes realizam suas atividades na própria floresta, de modo especial por que isso dispensa a coleta e o transporte do coco.

As quebradeiras podem produzir o carvão da casca do coco no próprio local da quebra, de forma que o transporte das amêndoas e do carvão fica mais fácil, pois o produto possui menos peso do que o coco babaçu "in natura", e os gases produzidos pela carbonização da casca seriam dispersos no ambiente em local distante das residências.

Os gases resultantes da fabricação de carvão vegetal, madeira ou coco babaçu, podem resultar em riscos à saúde e segurança do dos trabalhadores, dentre elas, irritação nas mucosas das vias aéreas, asfixiamento e toxidez que reduzem a capacidade de transporte de oxigênio para o cérebro, com redução da acuidade visual. Além disso, alguns desses elementos como o alcatrão, que é cancerígeno, podem provocar danos irreversíveis à saúde (Lima et al., 2000).

As condições em que o babaçu é beneficiado, aliadas ao preço pago pelo mercado, não se apresentam como atrativo. Se muitas quebradeiras artesanais ainda se dedicam à profissão, é porque não dispõem de outras formas de sobrevivência. O preço pago pelo quilo de amêndoas de babaçu no Estado do Tocantins, em 2013, é R\$1,80. Neste caso, uma quebradeira que extraia cinco quilos de amêndoas por dia, recebe a remuneração de $\mathrm{R} \$$ 9,00. (CONAB, 2013). 
A dedicação à profissão, além de não contribuir de forma adequada para a melhoria da qualidade de vida, não confere um status socioeconômico mais significativo, o que pode gerar insatisfação com o trabalho.

Tabela 3. Problemas de saúde já apresentados pelas quebradeiras de coco babaçu associadas à ASMUBIP no município de São Miguel, Estado do Tocantins, Brasil $\left(\mathrm{N}^{\circ}\right.$ de informantes $\left.=31\right)$.

\begin{tabular}{lcc}
\hline Item & Frequência & $\%$ \\
\hline Dores ósteo-musculares & 14 & 45,2 \\
Dor na espinha dorsal & 26 & 83,9 \\
Dores musculares & 11 & 35,5 \\
Dores em articulações & 17 & 54,8 \\
Dores em membros superiores & 14 & 45,2 \\
Dores na região cervical & 18 & 58,1 \\
Astenia (fraqueza generalizada) & 08 & 25,8 \\
Contusões & 28 & 90,3 \\
Amputação de membro durante o & 02 & 6,5 \\
trabalho & 08 & 25,8 \\
Respiratório & 01 & 3,2 \\
Doenças de pele & 01 & 3,2 \\
Dores de estômago & 148 & 100,0 \\
\hline TOTAL & &
\end{tabular}

Muitos desses sintomas (Tabela 3) são apresentados tanto por mulheres quanto por trabalhadores rurais do sexo masculino, dentre os quais, exposição contínua ao à ação dos raios solares, o que pode resultar em envelhecimento precoce e câncer de pele, posturas inadequadas que podem concorrer para o desenvolvimento de doenças ósteo-musculares e as mutilações provocadas por instrumentos de trabalho cortantes (Brasil, 2010).

Como se observa na Tabela 3 , são muitos os sintomas apresentados pelas informantes. Claro que alguns desses sintomas podem não estar relacionados apenas a sua dedicação à quebra do babaçu, mas podem se dever à idade e a fatores ambientais e higiênico-sanitários, tendo inclusive, uma das informantes comunicado ter tido, em momento anterior, diagnóstico positivo para hanseníase.

O diagnóstico de doenças relacionadas ao trabalho não é simples, uma vez que tais doenças podem ser desenvolvidas a partir de outras variáveis. Tanto é, que dos quatro grupos de doenças que acometem de forma mais frequente o trabalhador, de igual forma podem acometer outras categorias de pessoas, independente do tipo de atividade que realize.

Um exemplo são as doenças crônicas, degenerativas, infecciosas e traumáticas. Algumas doenças como a hipertensão e diabetes, que não são decorrentes da atividade profissional, podem ser agravadas pelo trabalho. Além disso, doenças que podem ser comuns a qualquer pessoa, como a asma, a bronquite e as reações alergênicas de qualquer ordem, podem ser agravadas em decorrência da atividade profissional (Brasil, 2001).

Assim, não seria simples relacionar algum tipo de adoecimento que acomete o trabalhador em geral com a atividade profissional que ele desenvolve, uma vez que tal adoecimento, por diversas outras causas, poderia ser desenvolvido por qualquer pessoa. 
De forma igual, não seria fácil atribuir os sintomas apresentados pelas quebradeiras de babaçu à sua atividade, o que não implica descartar essa possibilidade.

Tendo em vista a forma rudimentar em que as atividades que envolvem a quebra e beneficiamento das amêndoas do coco, bem como a fabricação do carvão de babaçu, inclusive porque as quebradeiras, na realização de sua atividade diária estão expostas a condições ambientais e sanitárias adversas, como fumaça produzida pela carbonização da casca do coco e poeiras de origem animal e vegetal que podem contribuir para um quadro de adoecimento (Faria et al., 2006).

As atividades rurais, entre elas a quebra do coco babaçu, expõem os trabalhadores a risco de adoecimentos por diversos agentes. Assim, admite-se que muitos dos sintomas informados acima podem estar relacionados à atividade da coleta, quebra e processamento do babaçu, o que contribui para o processo de adoecimento das quebradeiras de babaçu.

\section{CONCLUSÃO}

Os dados coletados através da pesquisa empírica conduzem à conclusão de que há relação entre o processo de adoecimento das quebradeiras e a quebra artesanal do coco babaçu, tanto é que elas apresentam sintomas que podem ser decorrentes de sua atividade laborativa.

A quebra artesanal do coco babaçu é realizada com instrumentos tecnológicos rudimentares e exige grandes esforços físicos das quebradeiras. Além disso, a coleta e a quebra são realizadas em ambientes insalubres, o que expõe as quebradeiras a riscos de adoecimentos, inclusive aqueles provenientes de posturas inadequadas e de acidentes de trabalho.

\section{REFERENCIAS}

ALBIERO, D.; MACIEL, A. J. D. S.; LOPES, A. C.; MELlO, C. A.; GAMERO, C. A. Proposta de uma máquina para colheita mecanizada de babaçu (Orbignya phalerata Mart.) para a agricultura familiar. Acta amazônica, v. 37, n. 03, p. 337-346, 2007. http://dx.doi.org/10.1590/S0044-59672007000300004

BARDIN, L. Análise de conteúdo.São Paulo: Edições 70, 2011.

BORELLI, A. Quebradeiras de coco de babaçu: raízes culturais ameríndias e africanas presentes nas estratégias de produção e luta em prol da preservação dos babaçuais da Amazônia (1989 a 2010). Jus Humanum: Revista Eletrônica de Ciências Jurídicas e Sociais, v. 1, n. 2, 2012.

BRASIL. Câmara dos Deputados. Decreto no 535, de 20 de Maio de 1992. Cria a Reserva Extrativista do Extremo Norte do Estado do Tocantins. Diário Oficial [da] União, Seção 1, 09 jun. 1992 , p. 7236.

BRASIL. Ministério da Saúde. Secretaria de Gestão Estratégica e Participativa. Departamento de Apoio à Gestão Participativa. Saúde da mulher: um diálogo aberto e participativo. Brasília, 2010. (Série B: Textos básicos de saúde).

Brasil. Ministério da Saúde do Brasil; Organização Pan-Americana da Saúde. Doenças relacionadas ao trabalho: manual de procedimentos para os serviços de saúde. Brasília, 2001. 
COPANHIA NACIONAL DE ABASTECIMENTO - CONAB (Brasil). Amêndoa de babaçu: preço pago ao extrativista (em $\mathrm{R} \$ / \mathrm{kg}$ ). Disponível: https://goo.gl/czwkpz Acesso em: 4 maio 2013.

DIAS, E. C. Condições de vida, trabalho, saúde e doença dos trabalhadores rurais no Brasil. In: PINHEIRO, T. M. M. (Org.). Saúde do trabalhador rural (RENAST). Disponível em: https://goo.gl/USL09x. Acesso em: 27 dez. 2012.

DIAS, L. de O. Interseções de gênero: mulheres quebradeiras de coco e a geração de vidas solidárias. In: SEMINÁRIO DE TRABALHO E GÊNERO PROTAGONISMO, ATIVISMO, QUESTÕES DE GÊNERO REVISITADAS, 4., 2012, Goiânia. Anais... Goiânia: UFG; UFU, 2012.

FARIA, N. M. X. et al. Trabalho rural, exposição a poeiras e sintomas respiratórios entre agricultores. Revista de Saúde Pública, v. 40, n. 5, p. 827-836, 2006. http://dx.doi.org/10.1590/S0034-89102006005000006

INSTITUTO BRASILEIRO DE GEOGRAFIA E ESTATÍTICA - IBGE. Cidades: Tocantins: São Miguel do Tocantins. 2010.Disponível em: http://cod.ibge.gov.br/XE2. Acesso em 28 set. 2012.

LIMA, A. A. C. et al. Solos e aptidão agrícola das terras do estado do Tocantins. Fortaleza: Embrapa Agroindústria Tropical, 2000.

MIRANDA, I. P. A.; RABELO, A; BUENO, C. R.; BARBOSA, E. M.; RIBEIRO, M. N. S. Frutos de Palmeiras da Amazônia. Manaus: INPA, 2001. p. 104-105.

OLIVEIRA, B. R. G. de.; MUROFUSDE, N. T. Acidentes de trabalho e doença ocupacional: estudo sobre o conhecimento do trabalhador hospitalar dos riscos à saúde de seu trabalho. Revista Latino-Americana de Enfermagem, v. 9, n. 1, p.109-115, 2001. http://dx.doi.org/10.1590/S0104-11692001000100016

PINTO, A. et al. Boas práticas para manejo florestal e agroindustrial: produtos florestais não madeireiros: açaí, andiroba, babaçu, castanha-do-brasil, copaíba e unha-de-gato. Belém: Imazon, 2010.

PORTO, M. F.; MILANEZ, B. Eixos de desenvolvimento econômico e geração de conflitos socioambientais no Brasil: desafios para a sustentabilidade e a justiça ambiental. Revista Ciência \& Saúde Coletiva, v. 14, n. 6, p. 1983-1994, 2009.

SATO, L. et al. Psicologia e saúde do trabalhador: práticas e investigações na Saúde Pública de São Paulo. Estudos de Psicologia, Natal, v. 11, n. 3, p. 281-288, 2006. http://dx.doi.org/10.1590/S1413-294X2006000300005

SANTOS, R. O Projeto Grande Carajás: seus reflexos para a cultura extrativista no Imperatriz: Ética, 2011.

SILVA, I. M. P. F. Impactos socioambientais da implantação de linha de transmissão de energia elétrica sobre as comunidades extrativistas do babaçu no Estado do Maranhão. 2006. 83p. Dissertação (Mestrado) - Universidade Federal do Pernambuco, 2006a.

SILVA, J. L. L. O processo saúde-doença e sua importância para a promoção da saúde. Informe-se em Promoção da Saúde, v. 2, n. 1, p. 3-5, 2006 b. 
SILVA NETO, N. M. da. Proteção local dos saberes tradicionais: as estratégias das quebradeiras de coco babaçu do Araguaia-Tocantins. In: CONGRESSO DO COPENDI, 17., 2008, Brasília. Anais... Florianópolis: COPENDI, 2008. 